\title{
Pitch-Matching Accuracy and Temporal Auditory Processing
}

\author{
Congeta Bruniere Xavier Fadel ${ }^{1}$ Angela Ribas ${ }^{2}$ Débora Lüders ${ }^{2}$ Vinicius Ribas Fonseca ${ }^{2,3}$ \\ Monica Nunes Lima Cat ${ }^{4}$
}

${ }^{1}$ Department of Pediatric Endocrinology, Universidade Federal do

Address for correspondence Congeta Bruniere Xavier Fadel, MD, Paraná, Curitiba, PR, Brazil

2 Post-Graduation Program in Communication Disorders,

Universidade Tuiuti do Paraná, Curitiba, PR, Brazil

3 Department of Otorhinolaryngology, Otorrinos, Hospital da Cruz Vermelha, Curitiba, PR, Brazil

${ }^{4}$ Post-Graduation in Children and Teenagers Health, Universidade

Federal do Paraná, Curitiba, PR, Brazil

Int Arch Otorhinolaryngol 2018;22:113-118.

Departamento de Endocrinologia Pediátrica, Universidade Federal do Paraná, Rua Padre Camargo, 250, Curitiba, PR, 80060-000, Brazil (e-mail: congetabxf@gmail.com; congetab@yahoo.com.br).

\begin{abstract}
Keywords

- auditory perception

- pitch discrimination

- hearing tests

- singing

- voice

Introduction Pitch-matching refers to the ability to vocally reproduce an acoustic model in a corresponding tone to the presented sound. This ability, which is dependent on pitch perception ability, can vary among individuals, and some are not able to sing in the correct tune or discriminate differences between tones.

Objective To correlate pitch-matching accuracy and auditory processing in individuals without musical training.

Methods A Pitch-Matching Test (vocal reproduction of synthesized and human voice sounds) and two commercially available tests of auditory temporal processing (the Pitch Pattern Sequence Test and the Random Gap Detection Test) were administered to all participants. A total of 62 college students of both genders, aged between 18 and 35 years old, were divided into 2 groups, according to their performances in the PitchMatching Test (the accurate match group and the inaccurate match group).

Results In the Pitch-Matching Test, both groups achieved better results when reproducing vocalized sounds. The accurate match group achieved a significantly higher pitch pattern sequence test performance. In the Random Gap Detection Test analysis, there were no differences between the two groups. The Pearson's chi-squared test showed a direct correlation between the Pitch-Matching Test and the Pitch Pattern Sequence Test.

Conclusion The findings of this study suggest the existence of a significant relationship between temporal auditory processing and pitch-matching, through which accurate pitch-matching individuals perform better in the Pitch Pattern Sequence Test. Inaccurate pitch-matching individuals may be skilled at discriminating pitch, despite their poor performance in the Pitch-Matching Test.
\end{abstract}

received

December 23, 2016

accepted

May 1, 2017

published online

June 13, 2017
DOI https://doi.org/

10.1055/s-0037-1603763. ISSN 1809-9777.
Copyright $(2018$ by Thieme Revinter

Publicações Ltda, Rio de Janeiro, Brazil
License terms

(c) (i) $\ominus$ (\$) 


\section{Introduction}

Pitch-matching refers to the ability to vocally reproduce an acoustic model in a corresponding tone to the presented sound, ${ }^{1}$ and involves the ability to listen accurately, differentiate the sound heard, store it, and finally reproduce it according to the given model. ${ }^{2}$

This ability, which is dependent on pitch perception ability, can vary among individuals, and some are not able to sing in the correct tune or discriminate differences between tones. This may be due to alterations that are organic, functional, ${ }^{3}$ or cognitive, ${ }^{4}$ and even be the result of a lack of exposure to music or some kind of musical training, which would cause difficulty in musical perception and/or lack of vocal mastery. ${ }^{1}$ However, to issue the pitches accurately, the auditory system must have functional integrity for peripheral components as well as central components, and the phonatory system must be functioning properly. ${ }^{4}$

The literature suggests that one of the processes in which the vocal pitch may be involved is the auditory feedback, such as in speech. When a person speaks, this feature is used as a monitor to obtain intelligibility and compliance with linguistic aspects, which are necessary elements in oral communication. When a person sings, this ability would act in controlling tone and timbre (or voice quality), and the individual would adjust the size/shape of the vocal tract as the need arises from the perception of the auditory feedback. ${ }^{5}$ Therefore, the individual would be able to compare his voice emission to reproduce the original sound model.

As for auditory temporal processing (ATP), this can be understood as the ability to perceive a sound or sound change within a period of time. ${ }^{6}$ As the basis for auditory processing, ATP refers to the perception of speech and music, and involves the power to render much of the information transmitted by means of sounds, such as the discrimination of frequencies. ${ }^{7}$

Most of the information that is transmitted via sound, such as speech and music, is produced by variations in sound characteristics with the passage of time. ${ }^{8}$ This temporal relationship, or "temporal information," would influence all the functions of the central auditory nervous system, acting as a mediator pattern of neural activity with a precision to the millisecond. This would occur because the temporal structure is the basis for the primary source of all hearing information signals. 9,10

Among the tests available for assessing ATP, the Pitch Pattern Sequence Test (PPST) and the Random Gap Detection Test (RGDT) were used in this study. The PPST was developed to assess the temporal ordering ability through the identification of the acoustic contours of sound stimuli. ${ }^{11}$ This test analyzes perception patterns, frequency discrimination, and linguistic naming when using verbal responses. ${ }^{12}$ The RGDT allows for the evaluation of the temporal hearing acuity threshold by detecting the lowest silence interval between two stimuli. ${ }^{13}$

With regard to the role played by the ATP in the pitchmatching ability, studies have shown that professional singers and instrumental musicians perform better in tests that evaluate temporal function ${ }^{14,15}$

Thus, the aim of this study was to investigate the relationship between pitch-matching accuracy and auditory processing in individuals with no musical training.

\section{Materials and Methods}

This is a clinical trial double-blinded study, which was approved by the Research Ethics Committee of one of our institutions under protocol number 725.256.

The study included 62 college students of both genders, aged 18 to 35 , who had no prior musical training. All participants were recruited randomly by invitation at a private university. We opted for such a sample because musicians perform better at central auditory processing tests because musical experience is characterized as auditory training. 15

The individuals included in the sample had normal hearing as confirmed by air-conduction pure tone audiometry testing at frequencies from 250 to $8,000 \mathrm{~Hz}$, and had normal vocal quality, which was aurally identified by the researchers. Subjects were excluded if they had technical or professional training in music.

After participating in a brief interview to collect identification data and in a voice perceptual auditory assessment, the respondents underwent pure tone audiometry. For the audiometric evaluation, hearing thresholds equal or better than $25 \mathrm{~dB}$ at frequencies of $250-8,000 \mathrm{~Hz}$ were defined as normal. $^{16}$

As a result, the volunteers who fulfilled the inclusion criteria underwent two tests with independent researchers: a) a Pitch-Matching Test (PMT); and b) ATP tests. A voice specialist applied the vocal PMT, and an expert in audiology applied the ATP tests. Neither side was aware of the results obtained in the tests applied by the other.

\section{Pitch-Matching Test}

The PMT is an evaluation procedure of pitch-matching ability, accomplished through vocal imitation of sounds of different tones perceived aurally. It is a sequence of 10 sound tasks, with the first 5 being of piano recordings (synthesized sound) and the last 5 recordings of the human voice (sounds of the vowel $/ \mathrm{u} /$ ).

From these sequences, six tasks are recordings of isolated tones in which the participant hears the sound and immediately tries to reproduce the tone by using the sound of the vowel / $\mathrm{u} /$; and four tasks are sequences of two sound stimuli presented consecutively in which the participant hears the two stimuli sequentially and reproduces them using the sound of the vowel $/ \mathrm{u} /$. The tones chosen for the sound pattern in the test were average and comfortable tones for both the male and female vocal ranges ${ }^{17}$ ( - Table 1 ).

For the recording of the piano sounds, an electronic synthesizer keyboard was used to enable the correct pitch of the tone. The sounds of the human voice were recorded by two professional musicians, a female singer, who performed the sequence of tasks for the female voice, and a male singer, 
Table 1 Order of stimuli for the Pitch-Matching Test

\begin{tabular}{|l|l|l|l|}
\hline Sequence & Source & Female Tones & Male Tones \\
\hline 1st & Piano & C4 & C3 \\
\hline 2nd & Piano & G4 & G3 \\
\hline 3rd & Piano & A4 & A3 \\
\hline 4th & Piano & D4 \& F\#4 & D3 \& F\#3 \\
\hline 5th & Piano & A\#4 \& F\# 4 & A\#3 \& F\#3 \\
\hline 6th & Voice & G4 & G3 \\
\hline 7th & Voice & D4 & D3 \\
\hline 8th & Voice & F\#4 & F\#3 \\
\hline 9th & Voice & A4 \& F4 & A3 \& F3 \\
\hline 10th & Voice & E4 \& G\#4 & E3 \& G\#3 \\
\hline
\end{tabular}

Notes: Source - Piano: sounds made by a digital piano; - voice: sounds made by female and male human voices

who performed the sequence for the male voice. The human voices were recorded in an acoustically arranged environment, and a keyboard played tones for the singers to use as a reference.

The vocal reproductions were captured using the CAKEWALK SONAR Producer Edition software (version 8.0.2, CakeWalk, Boston, USA), and the vocal samples were submitted to acoustic analysis through the VOCALGRAMA software (CTS Informática, Pato Branco, Brazil), version 1.8i, and they were compared with the tone originally presented.

A correct pitch was considered to be a vocal emission produced in the same frequency as the tone presented, and the success was calculated as follows: each of the 10 sound tasks was assigned a value of $10 \%$ to $100 \%$.

To drive correctly the sample to the two groups, the percentage of correct scores obtained in the tuning test (10 sound sequences) was taken into account: the accurate match group (AG), with more than $70 \%$ of correct notes, and the inaccurate match group (IG), which had less than $70 \%$ of correct notes. Such values were estimated from the verification of the performance of the sample in the reproduction of the tasks of the synthesized sound and human voice: 70\% of the individuals considered in tune have achieved a performance greater or equal to $60 \%$ of accuracy in the imitation of the stimuli produced by the piano, and $97 \%$ of this group have been able to reproduce in the correct tune at least $80 \%$ of the human voice sounds. The performance of the out of tune group was lower, with $70 \%$ of the individuals achieving a score $\leq 20 \%$ of correct sounds; $70 \%$ of them achieved up to $40 \%$ of correct responses to the human voice recorded stimuli.

\section{Auditory Temporal Processing Evaluation}

To assess ATP, the study used the RGDT and PPST. The PPST was held in monaural conditions. The subjects needed to verbally name the sequence of sound stimuli perceived: "high" for high-pitched stimuli, and "low" for low-pitched stimuli. Sequences of ten stimuli were delivered to each ear, attributing to each a value of $10 \%$ to $100 \%$ for each side. The normal range of this test suggests $90 \%$ accuracy in each ear evaluated. ${ }^{11}$

The RGDT was performed binaurally, and the subject was instructed to respond to stimuli nonverbally, that is, through gestures indicating if there were "one" or "two" stimuli. Nine pairs of intervals were presented in each of the four frequencies: $500 \mathrm{~Hz}, 1,000 \mathrm{~Hz}, 2,000 \mathrm{~Hz}$ and $4,000 \mathrm{~Hz} .{ }^{18}$ The normal range of this test suggests a perception $\leq 10 \mathrm{~ms}$ for individuals who are over the age of $7 .^{13}$

For the application of the tests, we used a CD player (Sony, Minato, Tokyo, Japan) connected to a MADSEN Itera II model two-channel audiometer with TDH-39 headphones (Otometrics, Taastrup, Denmark), calibrated according to the ISO 8253 standard, and a digital compact disk containing the tests for auditory processing. ${ }^{19}$

\section{Statistical Analyses}

Data were entered into spreadsheets and analyzed by an independent appraiser, which divided the sample by the result obtained in the PMT: accurate match group (AG) - composed of 28 participants considered to be have accurate pitch-matching (median $[\mathrm{M}]=24.4$ years, range 18-35); and inaccurate match group (IG) - composed of 34 participants considered to be inaccurate pitch-matching ( $\mathrm{M}=24.2$ years, range 18-35). Data from the ATP tests were analyzed considering the result of the PMT.

Statistical analyses were performed by means of descriptive and inferential methods, using the Statistical Package for the Social Sciences (SPSS, IBM Corp. Armonk, NY, US) software, version 20.0 (2011). The Wilcoxon test was applied to compare the medians within each group and the MannWhitney test between groups. Inter-rater agreement weighted Kappa was applied to estimate the performance of the agreement between the PMT and the PPST, and the Pearson's chi-squared test was used to compare the performance of the individuals on the PMT and PPST. The level of significance was set at $5 \%$.

\section{Results}

\section{Pitch-Matching Test}

- Table 2 shows the mean values and median of the correct tuning notes obtained by the AG and IG in the PMT. For a better understanding of the performance of the groups, the results were arranged into three categories:

1) Synthesized sound test - results obtained by the groups for the correct tuning of sounds with those produced by the digital piano;

2) Vocal sound test - results obtained by the groups for the correct tuning of sounds with those emitted by the human voice;

3) Total test - represents the total performance of the individuals in the full test (synthesized and vocal sounds).

There was a difference between the performances of the groups while reproducing the synthesized sounds versus the vocalized sounds. Both groups achieved better results when reproducing vocalized sounds. 
Table 2 Comparison between the number of correct responses in the PMT for synthesized and voiced sounds

\begin{tabular}{|c|c|c|c|c|c|c|c|c|c|}
\hline & \multicolumn{3}{|c|}{$\begin{array}{l}\text { AG } \\
(n=28)\end{array}$} & \multicolumn{3}{|c|}{$\begin{array}{l}\text { IG } \\
(n=34)\end{array}$} & \multicolumn{3}{|l|}{$\begin{array}{l}\text { AG and IG } \\
(n=62)\end{array}$} \\
\hline & $\begin{array}{l}\text { Mean } \\
\text { (SD) }\end{array}$ & Median & Min-Max & $\begin{array}{l}\text { Mean } \\
\text { (SD) }\end{array}$ & Median & Min-Max & Mean (SD) & Median & Min-Max \\
\hline Synt & $\begin{array}{l}62.9 \\
(20.9)\end{array}$ & 60 & $40-100$ & $\begin{array}{l}17.9 \\
(20.0)\end{array}$ & 20 & $0-60$ & $38.2(30.3)$ & 40 & $0-100$ \\
\hline Vocal & $\begin{array}{l}96.4 \\
(9.5)\end{array}$ & 100 & $60-100$ & $\begin{array}{l}34.1 \\
(30.2)\end{array}$ & 20 & $0-100$ & 62.3 (38.9) & 80 & $0-100$ \\
\hline$p$ & \multicolumn{3}{|c|}{$<0.001^{*}$} & \multicolumn{3}{|l|}{$0.01^{*}$} & \multicolumn{3}{|l|}{$<0.001^{*}$} \\
\hline
\end{tabular}

Abbreviations: AG, accurate match group; IG, inaccurate match group; SD, standard deviation; Synt, number of correct responses to synthesized sounds; Vocal, number of correct responses to vocalized sounds.

Note: *Wilcoxon test.

\section{Auditory Temporal Processing Evaluation}

The results of auditory temporal processing assessments may be viewed in - Table 3. We observed a difference for the PPST, in which the AG had a significantly higher performance.

- Table 4 shows the association between the performance of the individuals of the sample on the PMT and the PPST. We found that there was a direct correlation between the PPST and the PMT. In - Table $\mathbf{5}$ we can observe the concordance degree between the performance of the individuals of the sample on the PMT and the PPST. The results point to a substantial degree of concordance between the tests for good performance.

\section{Discussion}

The PMT results showed better overall performance for the participants in the two groups on the reproduction of sounds made by the human voice when compared with the synthesized sounds. This finding was observed in a study in which women were more accurate when asked to reproduce feminine vocal tones compared with the sounds of musical

Table 3 Comparison of the results for the Pitch Pattern Sequence and Random Gap Detection Tests for both groups

\begin{tabular}{|l|l|l|l|l|l|l|l|}
\hline \multirow{2}{*}{ Tests } & \multicolumn{2}{|l|}{ AG } & \multicolumn{2}{l|}{ IG } & $p$ \\
\cline { 2 - 7 } & $\begin{array}{l}\text { Mean } \\
\text { (SD) }\end{array}$ & Median & Min-Max & $\begin{array}{l}\text { Mean } \\
(\text { SD) }\end{array}$ & Median & Min-Max \\
\hline PPST (RE) & $\begin{array}{l}87.5 \\
(15.1)\end{array}$ & 90 & $50-100$ & $\begin{array}{l}60.3 \\
(30.2)\end{array}$ & 60.0 & $0-100$ & $<0.001^{*}$ \\
\hline PPST (LE) & $\begin{array}{l}88.2 \\
(15.6)\end{array}$ & 100 & $40-100$ & $\begin{array}{l}67.9 \\
(25.3)\end{array}$ & 70.0 & $20-100$ & $<0.001^{*}$ \\
\hline PPST (Mean RE \& LE) & $\begin{array}{l}87.9 \\
(14.8)\end{array}$ & 9.5 & $45-100$ & $\begin{array}{l}64.1 \\
(25.8)\end{array}$ & 67.5 & $20-100$ & $<0.001^{*}$ \\
\hline RGDT (ms) & $\begin{array}{l}6.5 \\
(3.3)\end{array}$ & 6.2 & $2.0-16.2$ & $\begin{array}{l}8.1 \\
(5.5)\end{array}$ & 5.9 & $2.7-25.0$ & $0.58^{*}$ \\
\hline
\end{tabular}

Abbreviations: AG, accurate match group; IG, inaccurate match group; LE, Left ear; ms, millisecond; PPST, Pitch Pattern Sequence Test; RE, right ear; RGDT, Random Gap Detection Test; SD, standard deviation.

Note: *Mann-Whitney test.

Table 4 Association between the performance of the individuals of the sample $(n=62)$ in the Pitch-Matching Test and Pitch Pattern Sequence test

\begin{tabular}{|l|l|l|l|l|l|l|l|}
\hline \multirow{2}{*}{ Tests } & \multicolumn{2}{l|}{$\begin{array}{l}\text { Poor } \\
\text { Performance }\end{array}$} & \multicolumn{2}{l|}{$\begin{array}{l}\text { Intermediate } \\
\text { Performance }\end{array}$} & \multicolumn{2}{l|}{ Good Performance } \\
\cline { 2 - 8 } & $\mathbf{n}$ & $\%$ & $\mathbf{n}$ & $\%$ & $\mathbf{n}$ & $\%$ & \\
\hline PMT & 22 & 35.5 & 12 & 19.3 & 28 & 45.2 & $<0.001^{*}$ \\
\hline PPST & 7 & 11.3 & 13 & 21.0 & 42 & 67.7 \\
\hline
\end{tabular}

Abbreviations: PMT, Pitch-Matching Test; PPST, Pitch Pattern Sequence Test.

Notes: Good Performance, 70-100\% of correct responses; Intermediate Performance, 40-69\% of correct responses; Poor Performance, 0-39\% of correct responses; 'Pearson's chi square test. 
Table 5 Concordance degree between the performance of the individuals of the sample $(n=62)$ in the Pitch-Matching Test and Pitch Pattern Sequence Test

\begin{tabular}{|c|c|c|c|c|c|c|}
\hline \multirow[t]{2}{*}{ Tests } & \multicolumn{2}{|c|}{$\begin{array}{l}\text { Poor } \\
\text { Performance }\end{array}$} & \multicolumn{2}{|c|}{$\begin{array}{l}\text { Intermediate } \\
\text { Performance }\end{array}$} & \multicolumn{2}{|c|}{ Good Performance } \\
\hline & $\mathrm{K}^{\mathrm{a}}$ & $p^{b}$ & $\mathrm{~K}^{\mathrm{a}}$ & $p^{b}$ & $\mathrm{~K}^{\mathrm{a}}$ & $p^{b}$ \\
\hline PMT (Synt) and PPST & 0.22 & 0.02 & 0.04 & 0.63 & 0.10 & 0.11 \\
\hline PMT (voice) and PPST & 0.04 & 0.66 & 0.04 & 0.70 & 0.37 & 0.001 \\
\hline PMT (Total) and PPST & 0.20 & 0.07 & 0.14 & 0.24 & 0.68 & $<0.001$ \\
\hline
\end{tabular}

Abbreviations: K, kappa; PMT, Pitch-Matching Test; PPST, Pitch Pattern Sequence Test; Synt, synthesized sounds; Vocal, vocalized sounds. Notes: Good Performance, $70-100 \%$ of correct responses; Intermediate Performance, $40-69 \%$ of correct responses; Poor Performance, 0-39\% of correct responses; Total, entire Pitch-Matching Test (synthesized and vocalized sounds); 'Weighted Kappa; ' $\mathrm{BcN}$ (mar's test.

instruments (violin and clarinet). The results of the study confirmed the hypothesis of the authors of a perceptual completeness of timbre and pitch, that is, a purely acoustic hypothesis that the timbre (spectral centroid) of the sound stimulus may influence the pitch-matching accuracy. ${ }^{20}$

Two other similar studies also corroborate this finding, but the authors associate this more accurate vocal reproduction to sensorimotor factors. ${ }^{21,22}$ According to the authors, the sound generated by the human voice allows the listener a direct access to a vocal gesture, that is, it promotes recognition of the biomechanical gesture of speech articulation, which would facilitate the imitative action.

As for the ATP tests, the analysis pointed to a significant difference between the performance of the two groups for the PPST, in which the AG achieved a higher percentage of correct answers. These same findings were obtained in a research involving musicians. ${ }^{14,23}$ The authors applied the PPST in groups of musicians and non-musicians (accurate and inaccurate pitch-matching) to compare their performances and draw from this result an association between vocal pitch and auditory processing. The results showed a better performance by the accurate subjects, and allowed the authors to conclude that the PPST is a sensitive test for the detection of possible malfunctions in the abilities of temporal processing in inaccurate pitch-matching individuals.

The PPST measures the sound frequency identification mechanism - an essential skill for recognizing and understanding musical melodies. Frequency identification depends on several central auditory processes, including the recognition of the whole, inter-hemispheric transference, linguistic naming, sequencing of the linguistic elements, and memory. ${ }^{24}$

The frequency discrimination process as beginning with the basilar membrane of the cochlea through tonotopic representation. According to the authors, the conscious recognition of this often only occurs in the primary auditory cortex of the temporal lobe in both hemispheres, first arriving in the contralateral temporal lobe of the stimulated ear. ${ }^{25}$

As for the RGDT results, the difference in performance between the groups was not significant. This result is in agreement with a study ${ }^{14}$ that showed no differences between the performance of accurate and inaccurate pitchmatching subjects on this test.
Regarding the relationship between pitch-matching and temporal auditory processing, the analyses indicated that there is a direct relationship between these abilities, especially in the population considered with accurate pitchmatching. Individuals who obtained $70 \%$ or more of correct reproductions in the PMT also obtained better auditory discrimination in the PPST ( $70 \%$ or better). This result demonstrates the possibility that, in this population (young students without musical training), the accurate pitchmatching individuals possess a more developed ability of perception of pitch patterns.

A detail that reinforces this assertion is the fact that the type of response required that the participants verbalized their responses to stimuli (high, low, for example) while performing the PPST, and not by imitation. The verbal response excludes the possibility of error in the test result due to the lack of control in the reproduction of the tone or pitch (since the subjects are not singers). If the answers were by imitation (by humming, for example), the test results could have been negatively influenced due to the lack of training of the participants (voice reproduction based on sound stimuli).

The relationship between fundamental frequency control skills and pitch discrimination abilities was studied in accurate and inaccurate untrained singers. ${ }^{26}$ The sample was subjected to two voice playback tests and one pitch discrimination test. The results showed a significant relationship between the pitch discrimination abilities and the accurate reproduction of the corresponding pitch. In another study ${ }^{27}$ about the relationship between the discrimination and the voice pitch, the authors investigated the role of corresponding pitch memory, and concluded that the relation is significant, suggesting a possible role for pitch memory in both tasks.

However, the findings of the present study also exclude the hypothesis that a developed discrimination ability would be sufficient to achieve pitch-matching because, according to the results, half of the individuals in the IG performed well in the PPST (giving 70\% or more correct answers), although this population performed poorly when compared with the AG. This finding is in accordance with a previous study ${ }^{28}$ that had the main objective of examining the relationship between pitch discrimination ability and pitch production ability in 
inaccurate adult singers. The authors observed in their sample two types of categories of inaccurate pitch-matching singers: those discriminating frequencies accurately but reproducing them inaccurately; and those that are not able to discriminate or reproduce, similarly to what occurred in the present study.

\section{Conclusion}

The findings of the present study suggest the existence of a significant relationship between temporal auditory processing and pitch matching, through which accurate pitchmatching individuals perform better in the PPST. Inaccurate pitch-matching individuals may be skilled at discriminating pitches, despite the poor performance in executing.

\section{References}

1 Sobreira S. Desafinação vocal. 2nd ed. Rio de Janeiro: Musimed; 2003

2 Watts C, Murphy J, Barnes-Burroughs K. Pitch matching accuracy of trained singers, untrained subjects with talented singing voices, and untrained subjects with nontalented singing voices in conditions of varying feedback. J Voice 2003;17(02):185-194

3 Brashears SM, Morlet TG, Berlin CI, Hood LJ. Olivocochlear efferent suppression in classical musicians. J Am Acad Audiol 2003; 14(06):314-324

4 Heresniak M. The Care and Training of Adult Bluebirds: Teaching the Singing Impaired. J Sing 2004;61(01):9-25

5 Moore RE, Estis J, Gordon-Hickey S, Watts C. Pitch discrimination and pitch matching abilities with vocal and nonvocal stimuli. J Voice 2008;22(04):399-407

6 ASHA. Central auditory processing disorders [Internet]. Rockville: American Speech-Language-Hearing Association; 2005. Available at: www.asha.org/policy/TR2005-00043. Accessed Feb 16, 2016

7 Samelli AG, Schochat E. Processamento Auditivo, Resolução Temporal e Teste de Detecção de Gap: Revisão da Literatura. Rev CEFAC 2008;10(03):369-377

8 Moore BCJ. An introduction to the psychology of hearing. San Diego: Academic Press; 1997

9 Allen P. Acoustics and Psychoacoustics. In: Roeser R, ed. Audiology Diagnosis. New York: Thieme Medical Publishers; 2000: 153-180

10 Schochat E, Andrade AN, Takeyama FC, et al. Processamento auditivo: comparação entre potenciais evocados auditivos de média latência e testes de padrões temporais. Rev. CEFAC 2009; 11(02):314-322

11 Musiek FE, Baran JA, Pinheiro ML. Neuroaudiology: case studies. San Diego: Singular; 1994

12 Shinn J. Temporal Processing and Temporal Patterning Tests. In: Musiek F, Chemak G. eds. Handbook of (Central) Auditory Processing Disorder. Auditory Neuroscience and Diagnosis. Vol. 1. San Diego: Plural Publishing, Inc.; 2007

13 Balen SA. Processamento auditivo Central: Aspectos Temporais da Audição e Percepção Acústica da Fala. [thesis]. São Paulo: PUC; 1997

14 Ishii C, Arashiro PM, Desgualdo L. Ordering and temporal resolution in professional singers and in well tuned and out of tune amateur singers. Pro Fono 2006;18(03):285-292

15 Monteiro RAM, Nascimento FM, Soares CD, Ferreira MDC. Habilidades de resolução temporal em músicos violinistas e não músicos. Int Arch Otorhinolaryngol 2010;14(03):302-308

16 Lloyd LL, Kaplan H. Audiometric interpretation: a manual of basic audiometry. Baltimore: University Park Press; 1978

17 Loiola CM, Ferreira LP. Coral amador: efeitos de uma proposta de intervenção fonoaudiológica. Rev CEFAC 2010;12(05):831841

18 Keith RW. Manual of The Random Gap Detection Test. St. Louis: Auditec; 2000

19 Auditec: Evaluation manual of pitch pattern sequence and duration pattern sequence. St. Louis: Auditec; 1997

20 Watts CR, Hall MD. Timbral influences on vocal pitch-matching accuracy. Logoped Phoniatr Vocol 2008;33(02):74-82

21 Lévêque Y, Giovanni A, Schön D. Pitch-matching in poor singers: human model advantage. J Voice 2012;26(03):293-298

22 Granot RY, Israel-Kolatt R, Gilboa A, Kolatt T. Accuracy of pitch matching significantly improved by live voice model. J Voice 2013; 27(03):390.e13-390.e20

23 Santos DG, Bouzada MAC. O Processamento Auditivo Central e a Desafinação Vocal. Inter Sci Place 2013;25(01):93-111

24 Pereira LD. Processamento auditivo. Temas Sobre Desenvolvimento 1993;2(11):7-14

25 Musiek FE, Pinheiro ML. Frequency patterns in cochlear, brainstem, and cerebral lesions. Audiology 1987;26(02):79-88

26 Watts C, Moore R, McCaghren K. The relationship between vocal pitch-matching skills and pitch discrimination skills in untrained accurate and inaccurate singers. J Voice 2005;19(04): 534-543

27 Moore RE, Keaton C, Watts C. The role of pitch memory in pitch discrimination and pitch matching. J Voice 2007;21(05):560567

28 Bradshaw E, McHenry MA. Pitch discrimination and pitch matching abilities of adults who sing inaccurately. J Voice 2005;19(03): 431-439 